\title{
Uma proposta para a produção de material didático de Língua Portuguesa com base no Letramento Visual para alunos surdos
}

\author{
A proposal for producing deaf student-oriented \\ Portuguese teaching material based on visual literacy
}

\author{
Elisângela Santos Mendes** \\ Rogério Soares de Oliveira**
}

\begin{abstract}
RESUMO: O presente artigo apresenta uma proposta de oficina de produção de material didático com base no Letramento Visual para alunos surdos, que, por apreenderem o mundo principalmente pela visão, precisam de uma metodologia que leve em consideração sua experiência visual. Além disso, recursos visuais, como slides, desenhos, história em quadrinho, vídeos e gráficos, são muitas vezes usados por professores de modo incipiente e sem constituir práticas reais de Letramento Visual, que supõem a análise crítica a partir de imagens. Nesta proposta, a oficina caracteriza-se como produto de uma pesquisa-ação, que, por sua vez, se delineia como uma pesquisa social comprometida em contribuir para solucionar problemas de ordem prática, considerados relevantes. A oficina foi construída a partir dos resultados levantados por meio de análise de dados obtidos com observação, notas de campo e respostas a um questionário semiestruturado aplicado com duas professoras de Língua Portuguesa de uma escola pública da cidade de Ipiaú/BA. Os resultados dessa intervenção apontam que as professoras buscam realizar práticas pedagógicas diferenciadas, na tentativa de atender ao aluno surdo em sua experiência visual de mundo. Evidenciou-se, ainda, que a oficina minorou as dificuldades de as professoras produzirem material didático mais imagético e despertou, nos alunos, mais interesse e maior participação nas aulas de Língua Portuguesa. O referencial teórico que embasa este trabalho está fundamentado em Santaella (2012), Ferraz (2012), Oliveira (2006), Lebedeff (2010) e outros autores.
\end{abstract}

PALAVRAS-CHAVE: Produção de material. Práticas pedagógicas. Letramento visual. Surdez.

\begin{abstract}
This article presents a workshop proposal for producing deaf student-oriented teaching material based on Visual Literacy. It taps into such students' primary understanding of the world primarily through sight and consequent need for a methodology that considers their viewing experience. It also departures from the fact that visual tools such as slides, drawings, comic strips, videos and graphics, are often used by teachers incipiently and do not constitute actual practices of Visual Literacy, which presupposes critical analysis of images. In this work, the workshop is an action research output, resulting from a socially oriented study committed to solving relevant practical problems. The workshop was based on results derived from the analysis of data obtained through observation, field notes, and application of a semi-structured questionnaire. The results show that teachers seek to perform innovative educational practices to meet deaf students' needs and visual experience of the world. Besides, the workshop lessened the teachers' difficulties in producing more imagistic teaching material and aroused in students more interest and participation in Portuguese classes. The work was based on the theoretical framework provided by Santaella (2012), Ferraz (2012), Oliveira (2006), Lebedeff (2010) and others.
\end{abstract}

KEYWORDS: Teaching material production. Pedagogical practices. Visual literacy. Deafness.

\footnotetext{
* Mestre em Letras Pelo Programa de Mestrado Profissional em Letras (PROFLETRAS) da Universidade Estadual de Santa Cruz (UESC). Atualmente trabalha no Centro de Apoio Pedagógico de Ipiaú - CAPI como professora de Língua Portuguesa para surdos desde 2012 (Secretaria de Educação da Bahia).

Professor Adjunto do Departamento de Letras e Artes da Universidade Estadual de Santa Cruz, professor do Mestrado Profissional em Letras.
} 


\section{Introdução}

A proposta de intervenção em forma de oficina que apresentamos neste artigo é resultado de uma pesquisa de mestrado intitulada "Um estudo sobre Bilinguismo e Letramento Visual no ensino de Língua Portuguesa escrita para surdos no Ensino Fundamental II", aplicada com professoras de Língua Portuguesa do $7^{\circ}$ e $9^{\circ}$ ano do Ensino Fundamental II de uma escola pública municipal na cidade de Ipiaú/BA, no ano de 2015. Nesta pesquisa, propusemo-nos a investigar como duas professoras de Língua Portuguesa (doravante LP) atuantes no Ensino Fundamental II da referida escola realizavam, ou não, prática pedagógica diferenciada em função de possuírem em classe alunos surdos usuários de uma língua visoespacial. Investigamos, ainda, em que medida a aplicação de oficinas de produção de material didático pôde contribuir para que essas professoras ressignificassem sua práxis docente na perspectiva do Letramento Visual (LV) e contemplassem as especificidades do aluno surdo que tem o Português como segunda língua.

Para tanto, foram estabelecidos dois objetivos gerais. O primeiro destinou-se a investigar em que medida essas professoras realizavam práticas metodológicas diferenciadas em função de possuírem em classe alunos surdos usuários de uma língua visoespacial. O segundo objetivo caracterizou-se por propor a essas docentes oficinas de produção de material didático que pudessem colaborar para que ressignificassem sua práxis pedagógica com foco no aluno surdo.

Trata-se de um produto resultante de pesquisa-ação, no campo da Educação. Tanto Tripp (2005) quanto Thiollent (2011) orientam que esse tipo de pesquisa colabore para que seus participantes produzam material que possa ser distribuído em maior escala. Além disso, trata-se de uma proposta exequível, simples, mas, ao mesmo tempo, significativa, cujo principal objetivo é despertar o interesse das docentes na realização de trabalho pedagógico voltado para o aluno surdo. Trabalhamos com a leitura de textos visuais, bem como com a produção e reescrita de textos verbais a partir de imagens, pois atividades de produção textual são comuns em todas as séries e os alunos surdos, assim como os ouvintes, também apresentam dificuldades na leitura e produção de textos. Outrossim, entendemos que a análise linguística pode ser realizada a partir das produções textuais dos alunos, uma vez que práticas de leitura e escrita são muito mais significativas quando partimos do uso efetivo da língua. 
Com o trabalho central voltado para a produção de texto escrito a partir de imagens, a oficina foi dividida em quatro encontros semanais, com duração média de duas horas cada, perfazendo um total de 8 horas-aula e obedecendo às seguintes temáticas:

- Encontro 1: O que é imagem? Como ler uma imagem?

- Encontro 2: O uso da imagem no contexto escolar.

- Encontro 3: A cognição visual dos surdos.

- Encontro 4: Análise da produção de textos de alunos surdos e proposta de reescrita.

Os encontros foram divididos em três importantes momentos. Primeiro, fizemos a apresentação teórica de cada tema; em seguida, abrimos espaço para discussões e perguntas; por fim, como característica intrínseca a uma oficina, destinamos um momento para que as professoras planejassem/produzissem materiais que pudessem servir para posterior trabalho com os alunos, como mapa conceitual, cartaz imagético, colagem, desenho, pintura e elaboração de propostas de produção textual a partir de imagens.

No tocante ao material e às atividades produzidas/utilizadas na oficina, tendo como base o $\mathrm{LV}^{2}$, utilizamos alguns recursos multimodais/multissemióticos e as Tecnologias da Informação e Comunicação (TIC), especialmente a $T V$ pen-drive, slides e vídeo, além de gravuras, símbolos e outros. Ressaltamos que o uso desses recursos visuais teve como principal meta instrumentalizar as professoras e auxiliá-las na identificação de quais estratégias visuais se adequam melhor à realidade de cada profissional e ao contexto escolar em que estão inseridas, pois acreditamos que "a função mais ampla do material didático é auxiliar a aprendizagem/aluno e, consequentemente, auxiliar o ensino/professor" (VILAÇA, 2009, p. 4). Cabe salientar que a mediação entre professor e aluno foi feita através de tradutorintérprete de Libras (TILS).

Entendemos que a produção de materiais didáticos visuais pode, de alguma forma, contribuir para a inserção de práticas sociais de leitura e de escrita entre os alunos surdos e os ouvintes, pois, segundo Nation (2001 apud PROCÓPIO; SOUZA, 2010), o uso de recursos visuais aliados a conceituações verbais pode favorecer a retenção do significado, tanto linguística quanto visualmente, ou seja, a apreensão de um código (visual) leva à aprendizagem de outro código (linguístico). Por essa razão, as práticas de LV precisam ser introduzidas nas escolas, especialmente quando possuem alunos surdos, pois a simples

\footnotetext{
${ }^{2}$ Uma discussão mais substancial sobre Letramento Visual será apresentada na próxima seção.
} 
exposição a material imagético não garante a construção e negociação de sentidos e do pensamento crítico.

Este artigo encontra-se dividido em três seções, além desta Introdução e das Considerações finais. Na Seção 2, discorremos sobre o LV e sua importância na educação dos surdos. Na Seção 3, descrevemos como se deu a oficina. Na Seção 4, divulgamos os principais resultados de nossa proposta de intervenção.

\section{Pressupostos teóricos sobre LV na educação de surdos}

Devido às profundas transformações sociais, econômicas, culturais e outras pelas quais passou (e tem passado) a sociedade nas últimas décadas, produzir e consumir imagem já faz parte do nosso cotidiano. Ela já não aparece como coadjuvante para meramente ilustrar um texto escrito. Ela é o próprio texto. A imagem carrega em si significados, talvez na mesma proporção, ou, a depender da situação comunicativa, em proporções maiores. Segundo Kress (1998 apud BURATINI, 2004, p. 2), há contextos em que a comunicação por imagens faz-se melhor do que por palavras, uma vez que a escrita já não é suficiente para atender às novas demandas sociais de comunicação.

Para Oliveira (2006, p. 4), “as configurações de significado deste início de século incluem modalidades que vão do código linguístico (escrito e verbal) tradicional, passando pelo visual, gestual, espacial proporcionando uma tendência multimodal ao ensinoaprendizagem". A leitura de textos visuais é uma prática necessária não apenas no contexto da língua materna, como também na leitura de textos escritos em segunda língua (L2) e em Língua Estrangeira (LE), pois “pode auxiliar a preencher possíveis lacunas de compreensão decorrentes de desconhecimento linguístico" (BURATINI, 2004, p. 11), lacunas que só poderão ser supridas "se (as imagens) tiverem um significado para os leitores" (BURATINI, 2004, p. 61), pois as imagens estão situadas dentro de um contexto cultural; logo, podem ser significativas para membros de dada cultura e não ser para outros.

O termo Letramento Visual provém do inglês visual literacy, também traduzido como “alfabetização visual”. Santaella $(2012$, p. 12) prefere esta tradução àquela, porque entende que o LV supõe que, "para lermos uma imagem, deveríamos ser capazes de desmembrá-la parte por parte, como se fosse um escrito, de lê-la em voz alta, de decodificá-la, como se decifra um código, e de traduzi-la, do mesmo modo que traduzimos textos de uma língua para outra". Concordamos com a autora; todavia, o termo Letramento Visual parece ser mais frequentemente usado no meio acadêmico. 
Para Santaella (2012, p. 13), o termo alfabetização visual

[s]ignifica aprender a ler imagens, desenvolver a observação de seus aspectos e traços constitutivos, detectar o que se produz no interior da própria imagem, sem fugir para outros pensamentos que nada têm a ver com ela. Ou seja, significa adquirir os conhecimentos correspondentes e desenvolver a sensibilidade necessária para saber como as imagens se apresentam, como indicam o que querem indicar, qual é o seu contexto de referência, como as imagens significam, como elas pensam, quais são seus modos específicos de representar a realidade.

O LV na educação de surdos prioriza a experiência visual desses sujeitos, que desde muito cedo fazem uso do canal de percepção visual para tentar significar tudo o que acontece ao seu redor. Lembramos que as línguas de sinais, pela natureza intrínseca de sua produção e recepção, são línguas visoespaciais; logo, podem ser "vistas" e atendem plenamente aos usuários que delas se utilizam. Por isso, ensejamos o uso desse tipo de prática na educação de surdos, não apenas para promover a aquisição da LP escrita, mas, sobretudo, para possibilitar e ampliar conhecimentos advindos de outras fontes.

Para Lebedeff (2010, p. 179), esse tipo de letramento é compreendido como "práticas sociais e culturais de leitura e compreensão de imagens", que precisam ser intencionais, escolarizadas ou não, pois, a simples exposição do aluno à imagem não garante a negociação de sentidos. Segundo a autora, há ausência de práticas baseadas na visualidade que permitam aos surdos se perceberem como sujeitos visuais, pois não há uma pedagogia que contemple a surdez.

Já, para Buratini (2004), a escola não prepara seus alunos para a leitura crítica de imagens, pois trata-se de uma deficiência no ensino de língua materna e de LE. Para ela, isso ocorre em razão do lugar de destaque que a escrita ocupa em nossa sociedade e em razão de a imagem não ser, para muitos educadores, considerada texto. Entretanto, Buratini (2004, p. 39) salienta: "faz-se necessária a preocupação com o Letramento Visual no ensino, principalmente porque a informação veiculada visualmente, tal qual a veiculada verbalmente, é sempre passível de interpretação".

Para muitos surdos, a apropriação da escrita passa primeiro pela visualidade, pois é por meio da língua de sinais e dos recursos visuais que o indivíduo surdo atribuirá significados para a leitura e para a escrita. Por essa razão, "as figuras devem ser relevantes para o aprendiz, além de familiares, ou seja, o aluno deve estar apto a falar a respeito da imagem, primeiramente, em sua língua materna" (CANNING-WILSON, 2001 apud 
PROCÓPIO; SOUZA, 2010, p. 96), e expressar percepções sobre o que a imagem evoca e os significados que a ela podem ser atribuídos.

Acreditamos que, de modo geral, nossos alunos (surdos e ouvintes) não sabem ler a imagem junto ao texto escrito para atribuir-lhe sentido, pois não foram ensinados a fazê-lo. Por esse motivo, faz-se necessário prover o aluno dessa habilidade, que deve ser ensinada, principalmente nas escolas. Obviamente, apenas a leitura de imagens não é suficiente para que um texto seja entendido por seu leitor, uma vez que "o processamento da informação textual acontece a partir de exposições a informações de diferentes fontes de conhecimento simultaneamente, quais sejam, conhecimento de mundo, ortográfico, lexical, sintático e de recursos gráficos em geral" (BURATINI, 2004, p. 18-19).

O LV pode favorecer o aprendizado da leitura e da escrita do texto verbal por meio da leitura crítica de imagens, aprimorando as capacidades bilíngues do surdo. Por esse motivo, deveria haver, nos cursos de formação de professor, a inserção desse tipo de letramento, uma vez que, segundo Soares (2012, p. 37), o letramento é capaz de mudar, no indivíduo, "o seu lugar social, seu modo de viver na sociedade, sua inserção na cultura, sua relação com os outros, com o contexto, com os bens culturais". E diz mais: "apropriar-se da escrita é tornar a escrita 'própria', ou seja, é assumi-la como sua propriedade" (soares, 2012, p. 39).

O uso das imagens no contexto da sala de aula visa promover a contextualização dos conteúdos, desenvolver as habilidades de ler textos não verbais, despertar o senso crítico sobre o que é visto, atribuir-lhe significados e ampliar o conhecimento de mundo de todos os estudantes, especialmente dos surdos, cuja ausência de uma língua compartilhada com a maioria dos interlocutores ouvintes nas mais diferentes situações de interação social (família, brincadeiras com os colegas e vizinhos e o que é veiculado nas mídias - TV, Internet etc.) pode acarretar enormes prejuízos ao seu desenvolvimento.

\section{Metodologia: a oficina como proposta para a produção de material didático}

Ao propor o termo oficina, concordamos com Santos $(2007$, p. 38) ao afirmar que "oficina é o local onde se exerce um ofício, com pessoas que comungam da mesma possibilidade de conhecimentos e habilidades, e onde se deve encontrar a matéria-prima para o trabalho que acontecerá". Entendemos que a "matéria-prima" principal deste trabalho sejam as professoras que aceitaram o desafio de oportunizar aos seus alunos, especialmente os surdos, uma sala de aula mais condizente com a forma como apreendem o mundo, ao mesmo 
tempo em que podem proporcionar aos alunos ouvintes aproximação com a língua, a cultura e as histórias de vida dos colegas surdos.

A proposta da oficina surgiu da necessidade de estudar e debater questões referentes ao ensino-aprendizagem dos alunos surdos, pois "na oficina é possível criar um espaço de trabalho e discussão, no qual todos os participantes se sintam mestres e aprendizes, construindo o conhecimento em sucessivas etapas coletivas e autônomas" (LEBEDEFF, 2010, p. 8). Pretendíamos, portanto, não apenas produzir material didático, que se torna irrelevante se o professor não tiver, sobre o seu aluno singular, um olhar diferenciado. Nossa intenção com a oficina foi dirimir dúvidas, desfazer equívocos a respeito do universo da surdez e discutir, com as profissionais, conhecimentos acerca das particularidades do aluno surdo, que necessita de estratégias de ensino que assegurem o seu direito de aprender.

Por material didático, concordamos com a definição de Freitas (2007, p. 21): "materiais e equipamentos didáticos são todo e qualquer recurso utilizado em um procedimento de ensino, visando à estimulação do aluno e à sua aproximação do conteúdo", isto é, todo e qualquer recurso, seja ele visual, auditivo, audiovisual ou em outra modalidade, que facilite a aprendizagem do aluno e otimize o trabalho pedagógico do professor. Lembramos que material didático não se restringe apenas ao livro didático (doravante, LD) e a materiais publicados (VILAÇA, 2009), apesar de reconhecermos que o LD é o recurso mais acessível ao professor e, talvez por esse motivo, o mais utilizado por ele em sala de aula.

Segundo Lebedeff (2010), tanto professores ouvintes quanto professores surdos, frequentemente, desenvolvem propostas educativas baseadas em ferramentas orais e não na visualidade. $\mathrm{O}$ fato de o surdo ser um indivíduo cuja experiência visual lhe é peculiar faz com que a autora ressalte a importância de o surdo acessar estratégias visuais de leitura e compreensão de mundo; daí a importância do LV como metodologia que melhor se adequa à surdez.

Retomando nossa proposta, os encontros ${ }^{3}$ foram realizados semanalmente na escola onde as docentes atuam em horários de AC (Atividade Complementar), na qual, primeiramente, se reúnem com outros professores de LP para atualização e produção de materiais, além de correção de atividades. O conteúdo priorizado para a realização desta proposta de intervenção foi a leitura de imagens, bem como a produção e retextualização de textos escritos a partir de textos imagéticos, pois a produção textual é atividade recorrente

\footnotetext{
3 A pesquisa está registrada no Comitê de Ética em Pesquisa com Seres Humanos sob o número CAAE 33900514.6.0000.5526.
} 
tanto no $5^{\circ}$ quanto no $9^{\circ}$ ano. Além disso, de modo geral, professores encontram dificuldades para realizar trabalho pedagógico com o aluno surdo e alguns estudos (BOTELHO, 2005; GUARINELLO, 2007; ALBRES, 2010) apontam as dificuldades que os alunos surdos têm de produzir textos com coerência na modalidade escrita da LP. Sabemos que os alunos ouvintes também apresentam dificuldades na feitura de textos em sua língua nativa, o Português. Por isso, podemos afirmar que este trabalho, a princípio elaborado especialmente para os estudantes surdos, pode também contemplar os estudantes ouvintes.

Ressaltamos que, neste trabalho pedagógico, a Libras (Língua Brasileira de Sinais) fez-se presente por meio da mediação dos intérpretes em sala de aula, não apenas para acessar o conteúdo verbalizado em LP (oral/escrita), mas por entendermos que a Libras é a língua natural da maioria dos surdos brasileiros, com a qual interagem com seus pares e por meio da qual o mundo lhe passa a fazer sentido. Entendemos também que o uso da palavra, conforme afirmam Silva, Kauchakje e Gesueli (2003, p. 163), é “fundamental, mas outros sistemas semióticos também podem exercer funções similares para a mente representacional humana, entre elas algumas linguagens viso-gestuais, como a língua de sinais”.

Orientamos as professoras para que preparassem suas aulas de acordo com o que foi discutido e elaborado em conjunto nos encontros e, posteriormente, aplicassem com seus alunos os roteiros, abaixo descritos, para que, nos encontros subsequentes, pudessem apresentar resultados/impressões sobre as aulas ministradas com materiais mais visuais.

\subsection{Encontro 1: O que é imagem? Como ler uma imagem?}

Partimos desse tema para averiguar qual era o entendimento das docentes acerca do que é imagem e como sua leitura se realiza (cf. Quadro 1). Nesse encontro, utilizamos, principalmente, aportes de Buratini (2004), Oliveira (2006) e Santaella (2012), porque julgamos importante apresentar e discutir os conceitos teóricos que dizem respeito ao LV.

Sobre este primeiro momento de intervenção, propusemos na prática a leitura imagética de uma pintura em tela para, conforme Santaella (2012), despertar no indivíduo a sensibilidade e os conhecimentos necessários para ler uma imagem. Embora pareça fácil ler uma imagem, o LV precisa ser aprendido. Por essa razão, discutimos que os textos visuais podem facilitar a leitura de textos escritos, especialmente em contextos de leitura e escrita de L2 e LE (BURATINI, 2004). Também fizemos uso de mapa conceitual, na tentativa de demonstrar que dado assunto/conceito pode ser mais bem apreendido quando 
informações/conhecimentos a ele referentes são visualmente organizados em forma de esquemas, gráfico, tabela, dentre outros.

Quadro 1 - Informações sobre o primeiro encontro

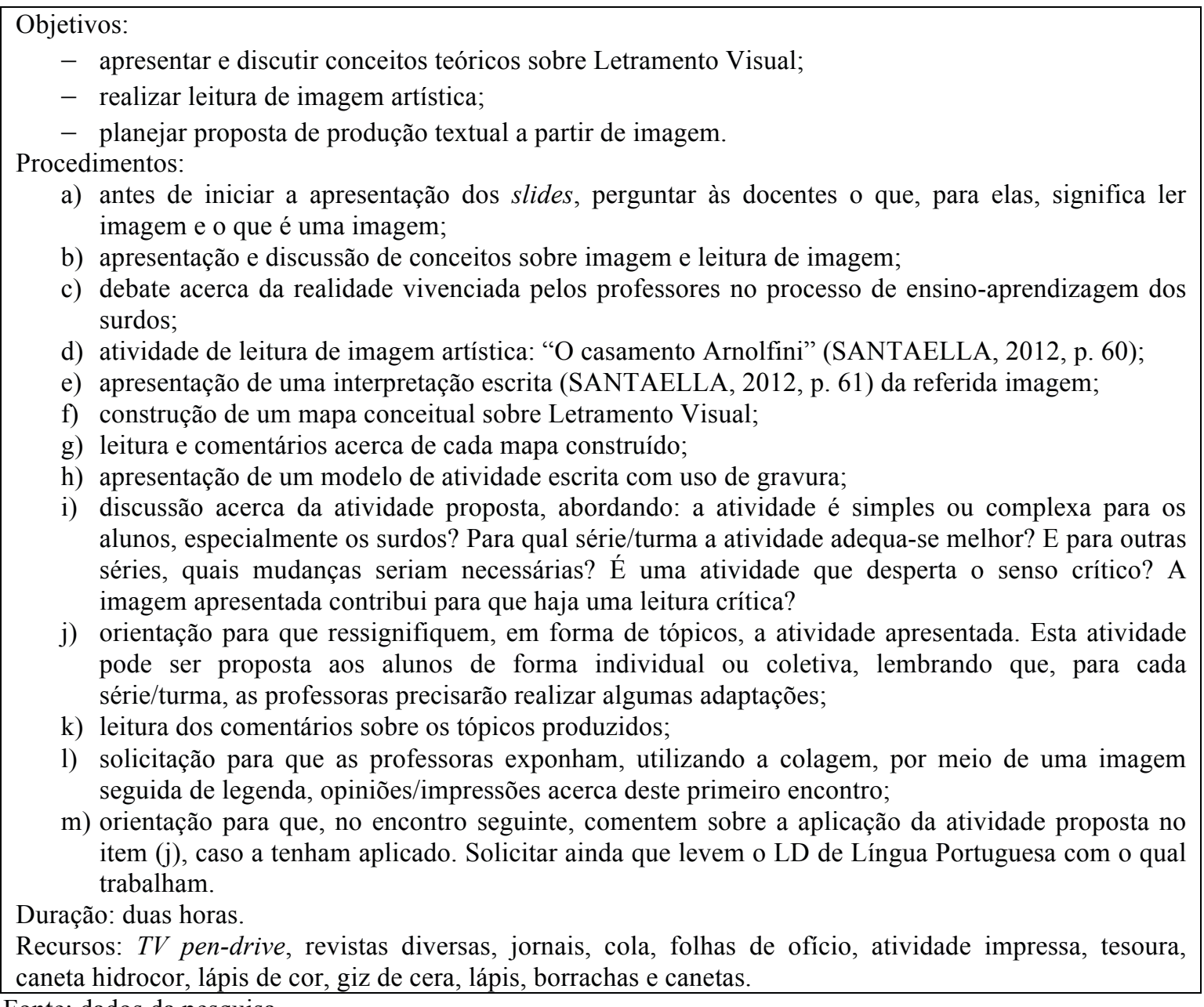

Fonte: dados da pesquisa.

Discorremos sobre como as representações visuais tentam significar os "aspectos do mundo visível" (SANTAELLA, 2012, p. 19) por meio de desenho, pintura, fotografia, gravura etc. Por fim, apresentamos uma atividade de produção textual a partir de imagem e sugerimos que as docentes a ressignificassem, levando em consideração que na sala de aula havia aluno surdo.

Além das nossas impressões, os comentários das professoras, bem como as discussões a partir da realização das atividades propostas, revelaram, por parte delas, curiosidade e interesse pelo tema da oficina. Nesse primeiro encontro, as discussões se estendiam, pois, 
frequentemente, as docentes associavam os conceitos apresentados com o conhecimento que tinham disponível acerca do universo da surdez e do seu aluno surdo.

\subsection{Encontro 2: O uso da imagem no contexto escolar}

No segundo encontro, discutimos a importância da imagem e seu uso em sala de aula, ao mesmo tempo em que buscamos situar historicamente o uso da imagem no cenário educacional, a partir dos autores Ferraz (2012) e Santaella (2012). Por essas razões trouxemos, para esse momento, a temática imagem no contexto de sala de aula (cf. Quadro 2).

Quadro 2 - Informações sobre o segundo encontro

Objetivos:
- refletir sobre a importância da imagem como recurso pedagógico no contexto escolar;
- $\quad$ produzir proposta de produção textual a partir de texto imagético.

Procedimentos:

a) antes de começar a apresentação dos slides, perguntar às professoras sobre o que pensam sobre o uso da imagem no contexto escolar por meio dos seguintes questionamentos:

- com que frequência vocês utilizam a imagem em sala de aula?

- que tipo de imagem vocês mais utilizam?

- na opinião de vocês, o uso da imagem é importante em sala de aula? Por quê?

- em se tratando da recepção por parte dos alunos, vocês percebem se há alguma diferença quando o conteúdo é abordado COM e SEM imagem?

b) apresentação e discussão acerca dos conceitos teóricos dos autores Santaella (2012) e Ferraz (2012) sobre o uso da imagem em sala de aula;

c) solicitação para que escolham um capítulo, atividade ou texto do LD que possua imagens;

d) proposta de breve análise do material escolhido com base no roteiro abaixo:

- a ilustração apresentada pode ser considerada atrativa? Convida o leitor à leitura?

- a imagem apresenta alguma ambiguidade em relação ao texto escrito?

- a imagem ajuda, de alguma forma, na compreensão do texto verbal? Em caso afirmativo, como a imagem colabora para o entendimento do texto escrito?

- também há imagens na atividade destinada à interpretação/compreensão do texto escrito? Se sim, como são apresentadas no livro?

- será que há, por parte das editoras, preocupação com as imagens apresentadas em seus livros? Justifique sua resposta.

- será que a imagem é usada apenas para complementar o texto escrito ou, em algum momento, a imagem parece ter mais importância que o texto verbal?

- o aspecto visual (capa, ilustração no interior do livro, diagramação, gráficos, tabelas, quadros etc.) do LD pode ter influenciado os professores para a sua adoção?

e) exposição das análises feitas;

f) discussão com as professoras sobre a maneira como cada uma trabalharia a ilustração analisada. Em seguida, pedir que elaborem proposta de como trabalhar com a referida ilustração a fim de contemplar o aluno surdo em sala de aula;

g) apresentação das propostas elaboradas;

h) orientação para que apliquem a proposta elaborada na aula seguinte. Os comentários/impressões serão apresentados no encontro subsequente;

i) solicitação, às professoras, que tentem ilustrar, por meio de desenho de um animal, um objeto, uma pessoa etc., suas impressões acerca deste segundo encontro.

Duração: duas horas.

Recursos: TV pen-drive, folha de ofício, atividades impressas, LD, caneta hidrocor, lápis de cor, giz de cera, lápis, caneta, borracha.

Fonte: dados da pesquisa. 
Nesse encontro, propusemos, por meio de um roteiro, breve análise das imagens de dado capítulo/atividade do livro didático que as docentes utilizavam, a fim de verificarmos qual o tratamento que o LD dá à imagem, pois era nossa intenção discutir a respeito da relevância, ou não, das práticas de LV no referido material. Assim como no primeiro encontro, também houve espaço para que as docentes socializassem suas dúvidas, opiniões e propostas elaboradas - essas, geralmente, eram seguidas de comentários das docentes e nossos também.

\subsection{Encontro 3: A cognição visual dos surdos}

Como queríamos discutir o aprendizado da LP pelo surdo tendo por base o uso de recursos visuais, julgamos conveniente abordar, no terceiro encontro, a cognição visual dos surdos e como o aprendizado dessas pessoas exige a visualidade que lhe é inerente. Por isso é tão premente que educadores de surdos aprendam a língua de sinais. Para discutir sobre o assunto, utilizamos o referencial teórico de Fernandes (2006) e Falcão (2010) e retomamos conceitos de outros autores estudados nos Encontros 1 e 2.

\section{Quadro 3 - Informações sobre o terceiro encontro}

\begin{tabular}{|l} 
Objetivos: \\
- $\quad$ refletir sobre o processo de cognição visual dos surdos como forma mais usada por eles para \\
atribuir significações ao seu redor; \\
- elaborar proposta de produção textual imagética e escrita. \\
Procedimentos: \\
a) antes de iniciar a apresentação teórica, fazer com as professoras uma pequena dinâmica na qual \\
devem dizer o nome da cor que estão vendo no slide 2 e não dizer a palavra escrita que representa \\
determinada cor; \\
b) leitura visual do slide 3, que retrata uma situação do contexto escolar na qual o aluno se vale da \\
cognição visual para responder a uma atividade proposta pelo professor; \\
c) apresentação teórica sobre a cognição visual dos surdos, como forma de apreensão do mundo, com \\
base em Falcão (2010); \\
d) espaço franqueado para perguntas e comentários; \\
e) exibição de vídeo em Libras legendado em Português com o tema "água", que será trabalhado pelas \\
professoras na Unidade III; \\
f) discussão e elaboração de atividade de produção textual imagética e escrita a partir do vídeo \\
apresentado; \\
g) solicitação para que, posteriormente, executem a atividade realizada com seus alunos; \\
h) avaliação deste terceiro encontro: as professoras farão uma pintura em tela com uma imagem \\
(abstrata ou não) que represente, para elas, as impressões sobre este encontro. \\
Duração: duas horas \\
Recursos: TV pen-drive, vídeo, papel de ofício, atividade impressa, lápis, caneta, borracha, tela (24 x \\
30 cm), tinta guache (várias cores), pincéis, toalha de papel, pires e copo plástico (para misturar as tintas e \\
lavar os pincéis).
\end{tabular}

Fonte: dados da pesquisa. 
Como nos encontros anteriores, após exposição teórica e discussão com as docentes, foi solicitada a elaboração de uma proposta de produção textual a partir de imagens. Fizemos também dinâmicas na tentativa de ilustrar o tema trabalhado neste encontro.

Para terminar a oficina, mais uma vez, solicitamos que as docentes representassem, por meio de pintura em tela, suas impressões acerca do penúltimo encontro. Fizemos uso desse tipo de atividade para aproximar a teoria discutida com a prática que desejamos que fosse vivenciada em sala de aula. Pretendíamos, também, trazer à baila que nem todos os alunos têm a habilidade de pintar ou desenhar. Por essa razão, faz-se importante que o professor considere o fato, ao tempo em que forneça outras formas de expressão ou de produção visual, como colagem, teatro, pequenos vídeos, fotografia e jogos.

\subsection{Encontro 4: Análise da produção de textos de alunos surdos e proposta de reescrita}

No quarto e último encontro, discutimos sobre como as marcas culturais das pessoas surdas influenciam na sua produção escrita. Por essa razão, o surdo apresenta escrita atípica em relação à de outros indivíduos. Todavia, não pode, em função disso, ser considerado uma pessoa incapaz de aprender. É preciso que levemos em consideração que ele se encontra em processo de aquisição de sua primeira língua (L1) e de uma L2 quase que simultaneamente e que essas línguas são de modalidades bem diferentes. Para tratar do assunto, utilizamos as obras de Albres (2010), Botelho (2005), Guarinello (2007), Koch (2011), Soares (2012) e Marcuschi (2003) $)^{4}$.

Verificamos que as docentes demonstraram maior apreciação desse encontro, talvez em razão de se tratar mais dos aspectos linguísticos; conceitos como pronome, preposição, coerência, coesão soavam-lhes mais familiar. Diferentemente dos anteriores, como avaliação desse encontro, utilizamos uma ficha impressa para avaliar toda a etapa de intervenção. Também consideramos os comentários e mensagem eletrônica posterior aos encontros. Nossas inferências acerca desse material encontram-se na próxima seção deste artigo.

\footnotetext{
${ }^{4}$ MARCUSCHI, L. A. Da fala para a escrita: atividades de retextualização. 4. ed. São Paulo: Cortez, 2003.
} 
Quadro 4 - Informações sobre o quarto encontro

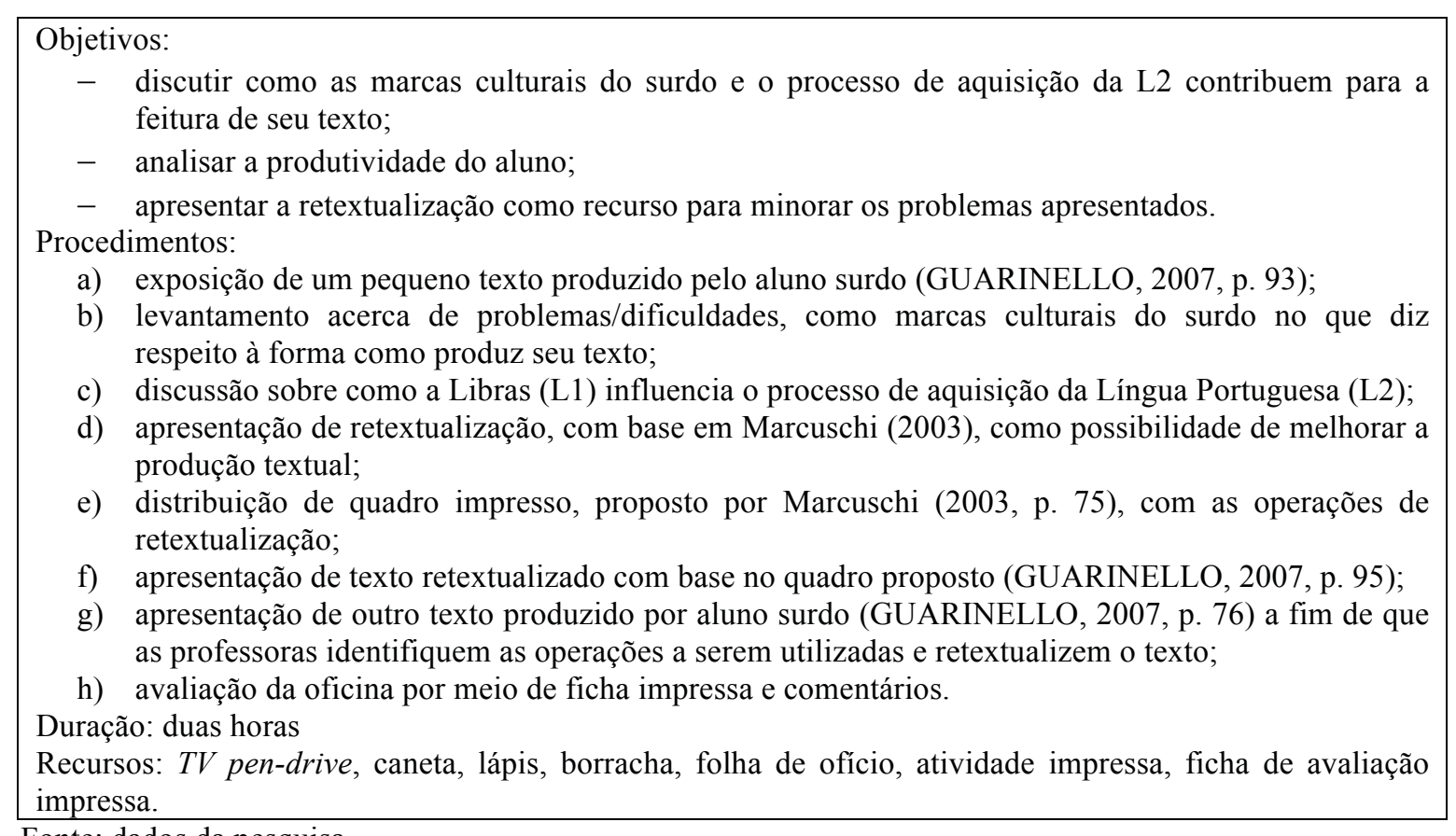

Fonte: dados da pesquisa.

\section{Resultados e intervenção}

Em se tratando de uma pesquisa-ação, cujo principal objetivo é, segundo Tripp (2005), o aprimoramento da prática, faz-se importante avaliar a eficácia dessa proposta a fim de otimizá-la e desfazer equívocos. Essa avaliação foi feita formalmente, por meio da aplicação de uma ficha de avaliação da oficina, respondida pelas professoras participantes e pelo registro de seus comentários durante a aplicação da oficina e de nossas impressões/observações.

No primeiro encontro, as professoras comentaram sobre a experiência de ensinar alunos surdos. Declararam ser esse um trabalho difícil de ser realizado, pois possuem dificuldades em elaborar atividades que contemplem esses alunos, especialmente as atividades referentes à análise linguística, leitura e compreensão de textos, e que, por tais razões, aceitaram participar da oficina, na esperança de que nela encontrassem orientação para a realização de trabalho pedagógico com o surdo.

Já no segundo encontro, o momento que julgamos mais significativo diz respeito à discussão levantada pelas docentes acerca da "inclusão" vivenciada pelos surdos no contexto da escola regular. Elas acreditam que, por mais esforço que façam na tentativa de ensinar LP a esses alunos, ainda há muitas lacunas. Afirmaram que os estudantes surdos aprendem de forma fragmentada e que elas (as professoras) não dominam a Libras. Soma-se a isso o fato 
de, na maioria das escolas públicas, haver carência de recursos diversos, a exemplo de material didático específico para surdos.

No terceiro encontro, as docentes comentaram sobre a ausência de interesse do poder público municipal em promover a capacitação profissional para o fomento de atividade pedagógica voltada para os surdos. Declararam, ainda, que a escola já promoveu algumas pequenas adaptações em seu currículo, como a seleção de materiais, entrega prévia dos conteúdos às intérpretes, elaboração de materiais na semana pedagógica, além da concretização de uma medida que julgamos bastante significativa: a implantação de uma aula de Libras uma vez por semana, ministrada pelos intérpretes nas salas em que atuam.

No quarto e último encontro, destinado, mais especificamente, à escrita e reescrita do texto do aluno surdo, as professoras alegaram que, apesar de reconhecerem a importância do processo de retextualização, trata-se de um procedimento impossível de ser desenvolvido na sala de aula da escola regular, geralmente numerosa, na qual precisam dividir sua atenção entre surdos e ouvintes. As docentes também afirmaram que esse tipo de atividade só pode ser realizado de forma individualizada, em aulas de "reforço", a exemplo do que acontece em centros/escolas que ofertam o Atendimento Educacional Especializado (AEE).

Já a ficha de avaliação conteve duas partes: a primeira, objetiva, possuía seis questões de marcar; a segunda apresentou uma estrutura na qual há uma pergunta aberta e uma solicitação de comentários/sugestões acerca da oficina. A parte objetiva ofereceu as seguintes possibilidades de resposta: "sim", "não" e "um pouco".

Das seis questões objetivas, ambas as professoras responderam "sim" a estas quatro: 1. A oficina atendeu às suas necessidades de formação para a realização de trabalho pedagógico com o aluno surdo?; 2. Foi possível aplicar, com seus alunos, alguma atividade produzida durante a oficina?; 3. Em caso afirmativo, você diria que a aplicação e os resultados foram positivos?; e 5. É preciso perceber ou afirmar que o uso da imagem no contexto escolar favorece, de fato, a aprendizagem dos alunos?

Entretanto, quando perguntadas: 4. Depois da oficina, foram minoradas as dificuldades para preparar material didático para trabalhar com aluno surdo? e 6. Durante a oficina, você teve dificuldade em confeccionar alguma atividade?, as respostas se dividiram. $\mathrm{P} 1^{5}$ marcou “sim”, enquanto $\mathrm{P} 2{ }^{6}$ marcou "um pouco", o que nos leva a entender que nossa proposta não

\footnotetext{
${ }^{5}$ Referência dada à informante 1.

${ }^{6}$ Referência dada à informante 2 .
} 
atendeu plenamente ao propósito de instrumentalizar as docentes na perspectiva do LV a fim de que produzissem e utilizassem, no contexto escolar, recursos mais visuais.

Entretanto, diante da maioria de respostas “sim", vimos, em linhas gerais, como positiva a avaliação, especialmente quando confirmadas pelas respostas às questões abertas a respeito dos aspectos positivos da oficina e das sugestões/comentários - estes pontuados apenas por $\mathrm{P} 2$ :

Colaborou bastante, tanto no aspecto de sugestões de estudos sistemáticos de teóricos, como também na potencialização da teoria, pois as sugestões disponibilizadas pela ministrante da oficina coloboram bastante para a prática educativa referente ao uso adequado de atividades condizentes às peculiaridades do aluno surdo. (P1)

As sugestões propostas/apresentadas foram bastante esclarecedoras, sobretudo com relação ao uso dos textos imagéticos e outros recursos que devem ser aplicados na elaboração das atividades. Pena que o tempo disponível foi muito limitado. Que essas oficinas sejam aplicadas em outros momentos. Sugiro mais propostas de atividades para trabalhar conteúdos gramaticais contextualizando-os. (P2)

Soma-se a isso o fato de ambas atribuírem o conceito "bom” à oficina. Também julgamos como positivos os trabalhos imagéticos por elas produzidos, quando, ao final da oficina, eram solicitadas a representar, por meio de uma imagem (colagem, desenho e pintura), as impressões que cada encontro promovia. Tais produções, a nosso ver, remetem às atitudes de questionar, criar, imaginar, estudar, desvendar e produzir o conhecimento que as imagens podem significar. Em se tratando de uma oficina de LV, consideramos importante que as professoras desenvolvessem a sensibilidade necessária para entender o quanto as imagens representam (SANTAELLA, 2012).

Quanto ao pouco tempo de realização da oficina, também exposto por P2, não foi possível estendê-lo em razão de vários entraves ocorridos na instituição escolar durante a aplicação da oficina. Por essa mesma razão, tornou-se inviável que as professoras aplicassem, em suas respectivas salas de aula, todos os planejamentos e materiais por elas produzidos. Apenas uma atividade foi aplicada. Todavia, mesmo se tratando da aplicação de uma única atividade e de seu relato, vimos que, de algum modo, os efeitos dessa intervenção foram positivos.

As professoras escolheram aplicar a proposta de produção textual resultante do primeiro encontro da oficina. P1, em seu relato, afirmou: 
Tal proposta foi bem satisfatória, pois atraiu o aluno surdo, que era o alvo principal, e também todos os alunos ouvintes. A participação do alunado foi plena e atuante, pois trabalhou sobre uma temática atual, embora o evento em destaque já ocorrera. Notei que, por meio de imagens, foi possível prender a atenção do discente surdo, algo bem difícil, pois pouca coisa o atrai. E no momento da produção (em grupo) todos participaram e variaram os tipos de produções. (grifos nossos)

Já P2, em sua avaliação da atividade, afirmou:

Confesso que gostei mais da exposição oral do que as produções escritas; embora eles não tenham fugido do tema, achei que a maioria foi evasiva. Também percebi que o aluno $\mathrm{X}$ participou mais das discussões do que a aluna $\mathrm{Y}^{7}$. Quanto às produções textuais, ambos expressaram, praticamente, as mesmas opiniões. Em comparação com as produções dos alunos ouvintes, as diferenças foram mais por conta dos componentes sintáticos/linguísticos do que pelo plano de expressão e do conteúdo temático.

Em nossa análise, o que fica mais evidente, por parte das docentes, é a compreensão sobre as reais práticas de LV e a necessidade de fornecer, aos alunos, as pistas necessárias para a leitura de uma imagem e, como consequência, o despertar do senso crítico, isto é, o entendimento dos alunos de que às imagens são atribuídos significados que, em uma leitura pouco atenta, passariam despercebidos. Notamos que isso ocorreu com P2, que precisou intervir na análise de seus alunos, indagar e oferecer outros elementos para que os estudantes desvelassem o que estava "por trás" da imagem.

\section{Considerações finais}

Compreendemos que nossa proposta de intervenção atendeu em parte aos anseios das docentes, pois elas manifestaram, especialmente na ficha de avaliação da oficina, que gostariam de que a análise linguística também tivesse sido contemplada em nossa proposta de intervenção. Inferimos, pela análise das respostas à ficha de avalição da oficina e dos comentários das docentes, que a intervenção influenciou positivamente em sua práxis, mesmo após seu término.

No entanto, as docentes expuseram que ainda sentem dificuldades em planejar/elaborar atividades que atendam aos surdos em suas especificidades. Entendemos que tais dificuldades podem ser decorrentes do pouco tempo de execução de nossa proposta, devido a entraves ocorridos durante sua aplicação. Além disso, a oficina por si só não seria capaz de resolver todos os problemas das docentes no que diz respeito a produção/elaboração de material, tampouco essa foi nossa pretensão. Objetivamos, contudo, minorar as

\footnotetext{
${ }^{7}$ Em substituição aos verdadeiros nomes dos alunos surdos, citados pela professora em seu relato de atividade.
} 
dificuldades apontadas. Compreendemos que os referidos obstáculos se apresentam em decorrência, principalmente, do não domínio da Libras, indispensável aos professores de surdos, que, ao menos, deveriam conhecer um pouco mais sobre as reais particularidades linguísticas, culturais e de aprendizagem desses seus alunos.

Entendemos que as práticas de LV trabalhadas durante a oficina contribuíram para que a práxis docente fosse, de algum modo, ressignificada. No entanto, compreendemos que a efetiva educação de surdos não se realiza apenas com a ação do professor. É preciso, além da mudança de postura docente, medidas que dizem respeito às políticas destinadas à inserção do surdo não apenas na sala de aula, mas em todo âmbito educacional por meio da criação de currículo voltado para as especificidades do surdo e projetos que valorizem sua experiência visual, especialmente por meio de sua língua e de sua cultura. Além disso, a Libras precisa existir como língua de instrução nas escolas e a LP, ser ensinada com metodologia de uma L2.

Sabemos que esta proposta de intervenção é, apenas, uma sugestão de trabalho pedagógico com uso de imagens que visa atender a um número maior de professores, especialmente se estes têm como aluno o indivíduo surdo. Que esses profissionais possam, cada vez mais, conhecer o universo linguístico, político e cultural de seu aluno surdo e que tentem promover, apesar da cruel realidade de exclusão em que vivem muitos estudantes de escolas públicas do Brasil, especialmente os surdos, um ensino no qual eles possam participar das aulas, questionar, criticar e reinventar a realidade na qual estão inseridos, desde que sejam instrumentalizados para fazê-lo.

\section{Referências}

ALBRES, N. A. Surdos e inclusão educacional. Rio de Janeiro: Arara Azul, 2010.

BOTELHO, P. Linguagem e letramento na educação dos surdos: ideologias e práticas pedagógicas. Belo Horizonte: Autêntica, 2005.

BURATINI, D. Z. Os recursos visuais na compreensão de leitura em língua estrangeira: reflexões sobre exames de vestibular. 2004. 160 f. Dissertação (Mestrado em Linguística) - Universidade de Campinas, Campinas, 2004.

FALCÃO, L. A. Surdez, cognição visual e Libras: estabelecendo novos diálogos. Recife: Ed. do Autor, 2010.

FERNANDES, S. Práticas de letramento na educação bilíngue para surdos. Curitiba: SEED, 2006.

FERRAZ, D. M. Letramento visual: a leitura de imagens nas aulas de Inglês. Jundiaí: Paco Editorial, 2012.

FREITAS, O. Equipamentos e materiais didáticos. Brasília: Universidade de Brasília, 2007. 
SILVA, I. R.; KAUCHAKJE, S.; GESUELI, Z. M. (Org.). Cidadania, surdez e linguagem: desafios e realidades. São Paulo: Plexus Editora, 2003.

GUARINELLO, A. C. O papel do outro na escrita de sujeitos surdos. São Paulo: Plexus, 2007.

KOCH, I. V. Escrita e interação. In: Ler e compreender: os sentidos do texto. 2 ed. São Paulo: Contexto, 2007. p. 31-35.

LEBEDEFF, T. B. Aprendendo a ler "com outros olhos": relatos de oficinas de letramento visual com professores surdos. Cadernos de Educação, Pelotas, v. 36, p. 175-195, maio-ago. 2010. Disponível em: $<$ http://www2.ufpel.edu.br/fae/caduc/downloads/n36/08.pdf> $>$. Acesso em: 22 out. 2013.

OLIVEIRA, S. Texto visual e leitura crítica: o dito, o omitido, o sugerido. Linguagem \& Ensino, Pelotas, v. 9, n. 1, p. 15-39, jan.-jun., 2006.

PROCÓPIO, R. B.; SOUZA, P. N. Letramento visual no ensino-aprendizagem de vocabulário em língua estrangeira. The Especialist, São Paulo, v. 31, n. 1, p. 93-118, 2010.

SANTAELLA, L. Leitura de imagens: como eu ensino. São Paulo: Melhoramentos, 2012.

SANTOS, L. F. dos. O instrutor surdo em uma escola inclusiva bilíngue: sua atuação junto aos alunos surdos no espaço da oficina de língua brasileira de sinais. 2007. 89 f. Dissertação (Mestrado em Educação) - Universidade Metodista de Piracicaba, Piracicaba, 2007. Disponível em: $<$ https://www.unimep.br/phpg/bibdig/aluno/visualiza.php?cod=344> . Acesso em: 21 ago. 2015.

SOARES, M. Letramento: um tema em três gêneros. 3. ed. Belo Horizonte: Autêntica Editora, 2012.

THIOLLENT, M. Metodologia da pesquisa-ação. 18. ed. São Paulo: Cortez, 2011.

TRIPP, D. Pesquisa-ação: uma introdução metodológica. Educação e Pesquisa, São Paulo, v. 31, n. 3, p. 443-466, set.-dez. 2005. Disponível em: <http://www.scielo.br/pdf/ep/v31n3/a09v31n3.pdf $>$. Acesso em: 6 ago. 2015. DOI: http://dx.doi.org/10.1590/S1517-97022005000300009.

VILAÇA, M. L. C. O material didático no ensino de língua estrangeira: definições, modalidades e papéis. Revista Eletrônica do Instituto de Humanidades, v. 3, n. 30, p. 1-14, jul.-set. 2009. Disponível em: <http://publicacoes.unigranrio.br/index.php/reihm/article/viewFile/653/538>. Acesso em: 11 ago. 2015. 